\title{
An industry-inspired civil engineering curriculum
}

Barbara Turnbull PhD

Associate Professor in Environmental Fluid Mechanics, Department of

Civil Engineering, University of Nottingham, Nottingham, UK (Barbara.

Turnbull@nottingham.ac.uk)

This paper describes the design of an undergraduate civil engineering curriculum that uses industry approaches to personal professional development and problem-based learning to educate the graduates that industry needs. In contrast to traditional module-based assessment, this curriculum is assessed at a programme level, enabling evaluation of professional skills from early on. This also give coherence across the curriculum, with reduced assessment loads of improved quality. Educators have been allowed to focus on educating students in their broad understanding and skills, which will benefit their long-term employability and adaptability.

\section{Introduction}

Civil engineering education in universities needs to evolve continuously to ensure students are ready for an evolving industry. Educators are presented with an age-old dilemma between providing the skills that students will need for the jobs they will graduate into in the near future and preparing those students to be adaptable for the civil engineering jobs of the future.

Employers increasingly need diverse skills, including the skills that graduates will need in a few years' time that cannot even be conceived yet. Similarly, jobs that students might go into when they graduate may not exist when they are part-way through their careers. As such they need to have the resilience and ability to manage and make the most of these uncertainties (Nolan et al., 2019). The educational challenge is exacerbated as nurturing students from their school studies to 'oven-ready' consultants and site engineers is a task that has already become stretched.

Reflection and responsibility for personal development have been cornerstones of professional engineering practice for a long time and are essential as industry evolves with everincreasing speed. The Engineering Council Accreditation of Higher Education Learning Outcomes, 3rd edn (Engineering Council, 2014) learning outcomes for accredited programmes that lead to chartered status have recently strengthened the requirements for personal skills of self-reflection, development and responsibility for learning. These skills link to a student's ability to evolve with industries of the future (Tittagala et al., 2016).

The question to ask in universities is how best to meet these learning outcomes and to train students in developmental reflection and personal responsibility for learning. This is challenging, especially when coupled with the superficially contradictory necessity of preparing students in particular and relevant skills for now.

Traditional modularised university courses can struggle to engender the thought processes, creativity and adaptability that students will actually come to depend upon when they are launched into the industry. Compartmentalising the curriculum by relatively narrow subjects means that students rarely see techniques or knowledge in the context of a wider engineering problem. Students may learn particular topics very well for the moment when they undertake an exam, but often cannot retain the information in the longer term nor understand when to use it in practical problems (Gibbs and Dunbar-Goddet, 2007).

In a modularised course, individual lecturers often try to be all things: showing the background, theory and application all within a small credit weighting. This leads to repetition and high assessment loads (Tomas and Jessop, 2018), because different assessment styles may suit each of those different aspects. The result is that students are more and more assessed, encouraging pragmatic learning to the test rather than embedding understanding for the long term. High assessment loads also reduce what should be an inspiring learning experience into a sequence of check boxes and a lack of flexibility to explore concepts that might not fit comfortably within the allocated credit weighting. This in turn limits the opportunity to challenge and stretch the best students. Timepoor lecturers can also 'hide' in their module because an individual often determines what is taught, how it is taught and how it is assessed; there can be little incentive to make improvements or to check for consistency and coherence with other parts of the curriculum.

To address the personal development-based learning outcomes of the Engineering Council, and in the student's future the Institution of Civil Engineers' (ICE) personal skills criteria, the University of Nottingham's Department of Civil Engineering has designed a new programme-level curriculum structure that departs from traditional, subject-specific modularisation (Gibbs and Dunbar-Goddet, 2007; Jessop and Tomas, 2017). Inspiration has been taken from industry approaches to personal development and problem-based tasks (Kyte, 2013), aiming to achieve four goals, to

- encourage students' understanding in the context of civil engineering as a whole

- prepare students for a challenging and transient jobs market by embedding professional attributes

- reduce the amount of assessment and improve its quality

- ensure that all students have a grounding in the basics, while providing opportunity for excellent students (the industry's future leaders) to be challenged and stretched. 


\section{Curriculum structure}

The new curriculum design has been implemented in steps since September 2016, with the first students who took the newly restructured first year then, now in their third year. The curriculum was developed in consultation with both current (some now recently graduated) students, whose views on coursework and assessment coherence and overload were one of the triggers to undertaking the task, and crucially with close input from the department's industrial advisory board. This is a board of industry leaders that sits regularly with department management, with oversight of management and curriculum decisions. The goal of the board is to ensure that the course meets the needs of industry and provides a strong connection with industry developments.

Inspired by industry approaches, the new curriculum is focused on the first and second years of the undergraduate course, years where the fundamentals of civil engineering are taught to all students. These two years start with students fresh from school with little idea of what civil engineering is and prepares them for their specialist options at the end of the course.

In the early, core years modules are now classified by assessment type rather than content (Van Der Vleuten et al., 2015), summarised in Table 1. The material is separated according to: technical content, assessed in a problem-based way to encourage students to recognise the connections between technical disciplines; skills that cut across technical subject boundaries taught within the framework of a personal development portfolio that specifically encourages and assesses professional attributes; and group projects that provide context and inspiration and embed group ethics.

In the first year, the student will be introduced to core technical knowledge in civil engineering (structures, hydraulics, geotechnics and mathematical methods). This is set in context through an introductory group project, and the skills to express knowledge and to develop personal attributes that embed a professional attitude are provided through the portfolio.

The student journey is similar in the second year, where the technical knowledge becomes deeper, the project more specific and challenging, and the skills portfolio broader. By their third and fourth years, students both specialise in particular applications of their core work and take optional modules in thematic subjects. By this time, the training of personal reflection, time management and individual skills from the portfolio should help students make the most of their individual research projects, their optional modules and the increasing challenge of group projects. The embedding of professional practice in the early years should therefore help students extract the most from their later years on the course.

Table 1. Summary of year 1 and 2 structure by assessment 'silos'

\begin{tabular}{|c|c|c|c|}
\hline Silo & Teaching & Assessment & Credits \\
\hline $\begin{array}{l}\text { Core technical } \\
\text { knowledge }\end{array}$ & Lectures & General exams & 60 \\
\hline Cross-disciplinary skills & Workshops & $\begin{array}{l}\text { Assignments } \rightarrow \\
\text { 'portfolio' }\end{array}$ & 30 \\
\hline $\begin{array}{l}\text { Context and } \\
\text { application }\end{array}$ & $\begin{array}{l}\text { Design } \\
\text { project }\end{array}$ & $\begin{array}{l}\text { Presentation and } \\
\text { report }\end{array}$ & 30 \\
\hline
\end{tabular}

\subsection{Skills portfolio}

The portfolio takes inspiration from engineering institutions' guidance on continued professional development (ICE, 2018) and is where professional attributes are embedded in the curriculum. It is recognised there are a number of skills that may be nice-to-have rather than need-to-know, and the decision on the cross-section of skills developed should lie with an individual student, determined by their career aspirations and aptitude. For example, some students would want to develop more skill in drawing and design, where others may be more interested in learning computational and numerical techniques (see Figure 1). One may aspire to become a design engineer, the other a developer of the next generation of building information models.

Students select which skills workshops they will undertake on a two-weekly cycle throughout the academic year, with the most in a single workshop capped at 40 students. This means that it is feasible to teach, for example, computer-aided design in a supported, personal environment. The choices are not arbitrary but must be rationalised by the student within a continuingprofessional-development-style plan that is regularly reflected on and updated in consultation with the student's personal tutor. A list of the skills workshops being offered to first and second years is appended in the online supplementary material that accompanies this paper.

The portfolio is also the home of core skills important across disciplines. For example, if a student sees information on professional ethics presented and assessed within a structures module, it can be difficult to disassociate that link in the future and understand the relevance to other topics. Within the skills portfolio, ethics can be delivered as a compulsory, non-compensatable, stand-alone workshop and assessment that demonstrates crossdisciplinary relevance.

Material from compulsory workshops is used elsewhere in the curriculum. For example, computer-aided design from the compulsory first-year workshop is used in the assessment for the surveying field course as well as in group projects from year 2 on; building information modelling learned in the year 2 building information modelling workshop is used in students' group projects the following year; and structural analysis programming

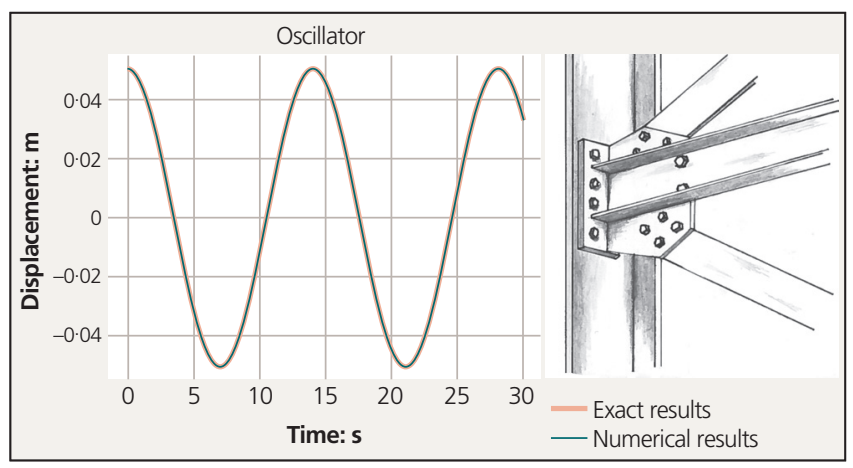

Figure 1. Examples of student work submitted or supported by their skills portfolio: an introduction to numerical analysis in the Python workshop and steel connection sketching. These illustrate how the portfolio covers both the science behind and the creative art of civil engineering 


\section{By having to navigate the workshop choices and justify those in personal reflection and development terms, students are starting to develop those attributes that the institutions place such importance on}

is deployed in core structures modules and some masters projects. Students discuss their future plans with their tutors to ensure that they take workshops that would strongly benefit particular optional module choices in their later years of study or particular career choices.

Workshops such as these are also ideal opportunities for industry to participate in the course. It has been fortunate to have a Royal Academy of Engineering professor in embedding professional skills, a leader in the industry, write and deliver some of the skills workshops on, for example, ethics, health and safety and project management. The students are thus exposed to real-life engineering projects and industry is given an opportunity to shape student education.

Crucially, the portfolio is where those professional skills attributes are honed. By having to navigate the workshop choices and justify those in personal reflection and development terms, students are starting to develop those attributes that the institutions place such importance on.

\subsection{Taught modules}

The taught modules cover the technical fundamentals of civil engineering (structures, geotechnics, hydraulics, materials science, and mathematical methods) assessed through a combination of targeted learning outcome-based standard questions and an advanced combined exam, with problem-based questions testing multiple modules within each question. A module mark comprises the grade achieved in the module-focused standard questions for that module, plus the overall grade achieved in the advanced combined paper, in a ratio of $70: 30$. A mark of $70 \%$ constitutes the grade boundary for a first-class degree. Thus, students achieving a first-class grade will need to have demonstrated attainment in the advanced learning outcomes of solving unfamiliar problems and combining techniques from across modules.

The department originally set the ratio for combining the standard:advanced paper grades at 60:40, representing the boundary between upper and lower second-class degrees, but after two iterations this was evidently too challenging. It is always difficult to perform to the limit of one's ability under exam conditions and it became clear that it was unreasonable to expect students at the limit of their abilities to achieve close to $100 \%$ in that standard exam. The 70:30 ratio in practice means that most students will be at or close to the upper and lower second-class boundary after the standard papers.

There are a number of reasons to combine the exam papers in this way. The aim is to encourage students to see their modules not in isolation, avoiding learning to the test and promoting a healthier culture of practice through the year and discouraging cramming. The peak performance may be expected to be lower, but students should have a wider range of concepts better consolidated. The advanced paper also offers a challenge to the very best students while making it clear for less-able students what is essential through the standard paper questions. The advanced paper is very much in the style of traditional institution exams, with questions in problem-based style. These really test the high-level skills of navigating new and uncertain problems, and combining knowledge from a wide base. Practically speaking, by having the assessments combined and at the end of the academic year, 3 weeks of exam period is recovered in the winter that can be used for focused project work.

Combining the examinations has also allowed tailoring of the mathematical methods that students encounter, so that they are taught methods in their mathematics as they use them within their civil engineering modules. For example, students see matrices in mathematics as they encounter linear systems in structures. Complex numbers and solving higher-order differential equations are left until they see them in vibrations and hydraulics in year 2 . Although the standard questions (as in class tests for mathematics) test the methods directly, students will need to apply those methods to civil engineering problems within the advanced paper.

\subsection{Group projects}

The main goals of the group projects are to offer inspiration, context, project management skills and to teach design. In the first year, context is vital because few students will have a complete concept of what a civil engineering project actually is. In that early stage, they need to be shown how a civil engineering project fits together from start to finish, and in particular how technical disciplines fit in.

In the second year, the project becomes more serious and is the main mechanism for introducing Eurocode-based design with focus on steel design. The skills individuals have developed within their portfolios start to be important here as a diversity of skills within groups allows different components to be optimised.

Tutors discuss with their groups where at least one student must have covered a particular skills workshop for the project to be delivered, appropriate skills coverage for the group being a consideration of an individual's development plan. Group projects remain important also in the later years of the course, with Table 2

Table 2. Summary of group project trajectory through the course

\begin{tabular}{|llll}
\hline Year 1 & Year $\mathbf{2}$ & Year 3 & Year $\mathbf{4}$ \\
\hline Introductory & The design process & Integrating building information modelling & Challenge-led \\
\hline Inspiring & Introducing the codes & Detailed construction plan & Beyond the codes \\
\hline Civil engineering context & Focus on steel & Focus on concrete & All of civil engineering \\
\hline
\end{tabular}


illustrating the progression of challenges within those projects, and how key elements of civil engineering are both introduced and consolidated through them.

\section{Review}

The students now in their third year of study have been the first to experience the first two years of this curriculum design and it is not possible yet to assess the success of this design against all of the goals set. This can only be understood fully at the end of the full course, as students go out into employment and develop over the years within that employment.

However, there have been two immediate benefits: first, quality control of exams has significantly improved. There is much less assessment of much higher quality. Four years ago, the department set nearly 50 exam papers, this year it will be 26 ; the number of coursework assignments is also rationalised. Multiple lecturers contributing to single questions on the same paper has led to much better awareness of each other's topics and styles, a true team teaching ethic. Exam questions are now consistent and a number of corner-cutting practices have been eliminated. Linked to this, the curriculum is evidently more coherent. Students now remark that they appreciate the links demonstrated between core modules and that they enjoy the challenge of the multi-disciplinary questions. Mohr's circle is taught jointly in geotechnics and structures and assessed in one exam. Students build wet and dry sandcastles and use Mohr's circle to draw out key concepts and the principle of effective stress. Students have fun trying to build the strongest sandcastles to underpin critical concepts, and there is time to do this because they are not constrained within a single module.

Second, compared with the work of the best students before the new curriculum, the best students are being stretched like never before, especially in the design projects (see Figure 2). They are contextualising their work to a much greater degree, demonstrating an holistic appreciation of civil engineering concepts and design; they have more interaction with real engineers through the flexibility of the portfolio; they have confidence in their creativity; they have a broader range of skills; they are calmer about time management. Thus, students are demonstrating through the course skills that industry values. These traits have been showing themselves as the students start applying for graduate jobs: they feel better prepared for industry, they find it more straightforward to show off their individual skills, they have a lot of experience of group and skills-based work to draw on to make their case for employment. An external examiner recognised that the curriculum has placed the department at the "cutting edge of civil engineering education'.

A downside has been staff workload, and in the first iteration students were probably asked for too much. However, staff teaching portfolio workshops feel more connected with the students. It is a less formal arena with smaller group teaching, and this is excellent both for students transitioning from school to university and also

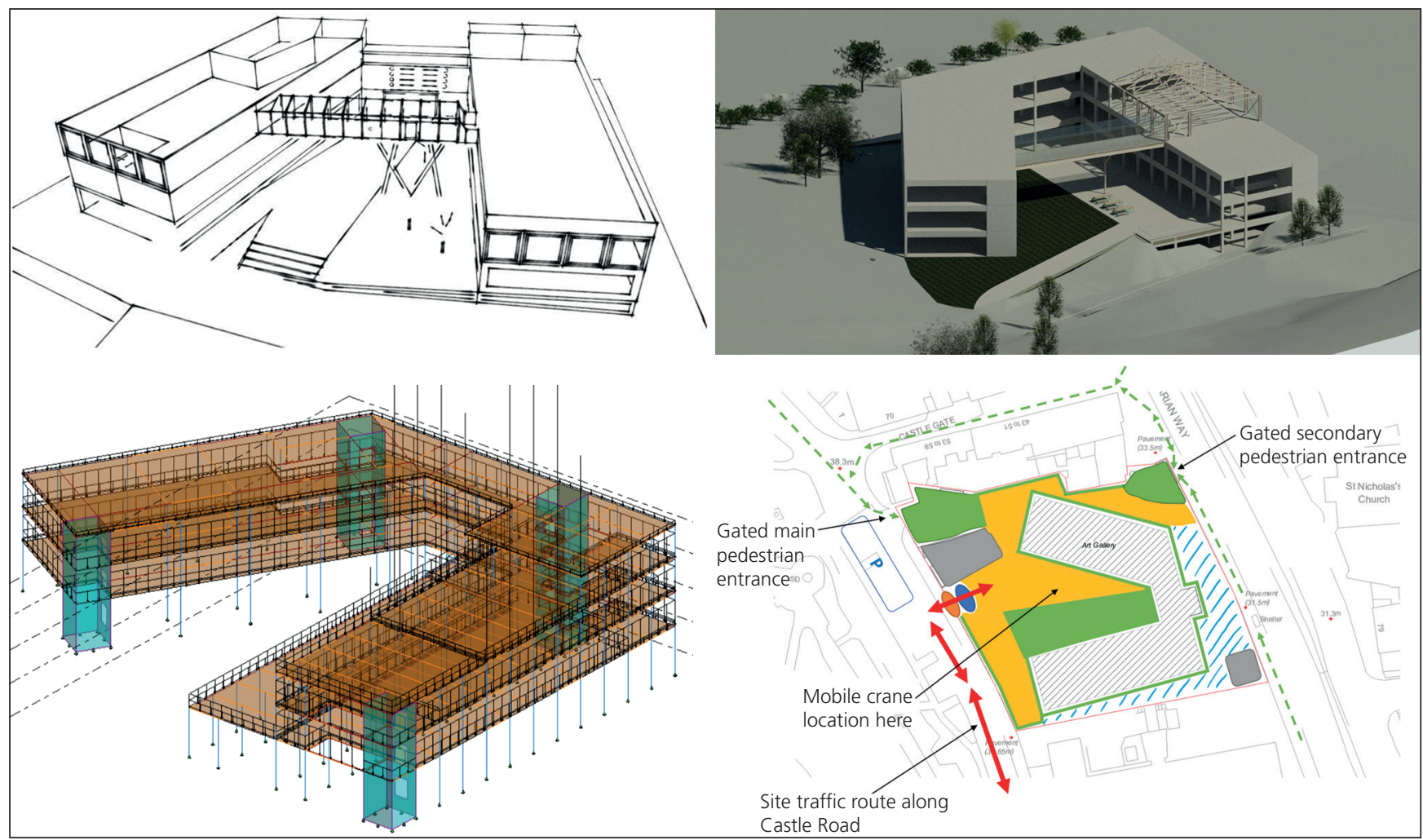

Figure 2. Example of a third-year group design project for a new, reinforced concrete art gallery in Nottingham. Students took the design from concept stage to detailed design stage with a construction management plan. These students were some of the first cohort to undertake the skills portfolio and group projects in all years of the course 


\section{Entrenching the process of personal review and choice in skills development can actually result in students taking more responsibility for their learning and being better prepared for industry}

for staff to get to know the students, spot potential issues early and try out new teaching techniques in a low-risk environment.

By organising the course through assessment types, the assessments are now better matched to the topics covered. Project management is taught through projects, sketching is taught by going out and sketching structures around the campus. A significant benefit has been that more challenging assessment types are no longer compensated by less challenging ones. A student can no longer boost their mark in structures by loosely controlled or associated coursework; the grade the student gets is from the examcondition testing of technical learning outcomes. This approach in the early years has better prepared students for the later years of the course: in their third year, where the assessment has been unchanged for a year, a higher proportion of students coming through the new course have achieved very high grades. In summer $2019,39 \%$ of students achieved a year 3 average of $70 \%$ or above (the first-class boundary), compared with $28 \%$ the previous year, with $12 \%$ of students achieving an exceptional year average of over $80 \%$, compared with $3 \%$ the previous year.

The department's overseas campuses (in Malaysia and China) have been whole-hearted in adopting this industry-inspired curriculum. This means that the changes can have impact not just on UK students but also internationally. As the students who helped to 'trailblaze', in the words of an external examiner, come to the end of their degrees, methods will be developed for a statistical understanding of whether the goals in changing the curriculum have been met. For now, the department has had to rely on anecdote. Students who have come through the industry-inspired curriculum have notably excelled in those personal management and skills areas that the portfolio and projects in particular target. For example

- 'We were very impressed with [the student's] work ethic and willingness to go the extra mile. [They] approached everything in a professional manner and had an excellent understanding of Revit'

- '[The student] displayed excellent professional skills during [their internship]. [They were] enthusiastic and keen to learn new skills. The work [they] undertook was to a high standard and completed on time. [They] also displayed good organisational skills managing [their] workload well and was proactive in keeping [themselves] utilised'

a '[The student] was outstanding. [They were] very enthusiastic and willing to learn. [They were] well organised and professional in [their] approach. We have offered [them] a scholarship as a result of [their] performance'.
The positivity suggests that entrenching the process of personal review and choice in skills development can actually result in students taking more responsibility for their learning and being better prepared for industry. By individualising skills choices students can focus on their skills for now, while developing the personal ability to learn new things later. There has been a benefit in terms of project quality and also employability of students having individual portfolios of skills. This is something they can take to an interview, much like a prospective architect might, that shows their style and substance in a demonstrable way. The early signs are promising.

\section{Acknowledgements}

The biggest contributors to the author's work here haves been the students, past and present. The creation and realisation of this curriculum has been a huge group undertaking by the Department, and the author wishes to thank Paul Ragsdale for his special support in identifying the graphics to present; Charles Heron and Martin Smith for their dedication to the discussions; all of the year 1 and 3 exam writers; and all my colleagues who have written and delivered Portfolio workshops when we had no idea what one might look like. Chris Lawrence (formerly of WSP | Parsons Brinkerhoff and RSSB) contributed hugely to developing the portfolio through a Royal Academy of Engineering Visiting Professorship (RAE grant VP1516-2-69). The author also thanks Carmen Tomas, assessment advisor and the teaching transformation team at the University of Nottingham for their support, and for the guidance and support of the department's industrial advisory board. Sean Carroll, now at the University of Exeter, contributed significantly to the early discussions that led to the curriculum design.

\section{References}

Engineering Council (2014) The Accreditation of Higher Education Programmes, 3rd edn. Engineering Council, London, UK.

Gibbs $\mathrm{G}$ and Dunbar-Goddet H (2007) The Effects of Programme Assessment Environments on Student Learning. The Higher Education Academy, York, UK.

ICE (Institution of Civil Engineers) (2018) Continuing Professional Development Guidance, 1(4) edn. ICE, London, UK.

Jessop T and Tomas C (2017) The implications of programme assessment patterns for student learning. Assessment \& Evaluation in Higher Education 42(6): 990-999.

Kyte A (2013) A 'fresh eyes' look at improving the effectiveness of engineering group design projects. Engineering Education 8(1): 81-97.

Nolan J, Russell N, Firth I and Ibell T (2019) There is more to a flower than a STEM. The Structural Engineer 97(1): 40-41.

Tittagala R, Hadidimoud S and Liang B (2016) Addressing the UK-SPEC competence levels: challenges in programme design and delivery in a diversifying engineering HE sector. In ISEE 2016 Sixth International Symposium on Engineering Education (Kapranos P (ed.)). University of Manchester, Manchester, UK, pp. 255-263.

Tomas C and Jessop T (2018) Struggling and juggling: a comparison of student assessment loads across research and teaching-intensive universities. Assessment \& Evaluation in Higher Education 44(1): 1-10.

Van Der Vleuten CPM, Schuwirth LWT, Driessen EW, Govaerts MJB and Heeneman S (2015) Twelve tips for programmatic assessment. Medical Teacher 37(7): 641-646. 